University of Wollongong

Research Online

Faculty of Social Sciences - Papers (Archive) Faculty of Arts, Social Sciences \& Humanities

2016

Digital play: Exploring young children's perspectives on applications designed for preschoolers

Irina Verenikina

University of Wollongong, irina@uow.edu.au

Lisa K. Kervin

University of Wollongong, Ikervin@uow.edu.au

Maria Clara Rivera

University of Wollongong, mcsr095@uowmail.edu.au

Alison Lidbetter

University of Wollongong

Follow this and additional works at: https://ro.uow.edu.au/sspapers

Part of the Education Commons, and the Social and Behavioral Sciences Commons

Research Online is the open access institutional repository for the University of Wollongong. For further information contact the UOW Library: research-pubs@uow.edu.au 


\title{
Digital play: Exploring young children's perspectives on applications designed for preschoolers
}

\author{
Abstract \\ This study builds on and contributes to research on digital play with young children. Previous research \\ has examined digital play from different viewpoints, but no studies have specifically addressed young \\ children's perspectives as they interact with applications (apps) that have been designed specifically for \\ their age group. While our review of the literature provides insights from investigations of young children's \\ perspectives, there is limited research on preschoolers' views on the apps designed for them by adults. In \\ this article, we discuss young participants' perspectives on the apps that they engaged with in our \\ research. In particular, we emphasise the importance of various contexts for digital play in relation to \\ meaningful conversations and social interactions. Our findings provide insights about how children \\ choose to engage in digital play and through this, pose implications for the design of apps.
}

\section{Keywords}

designed, applications, digital, perspectives, children's, young, exploring, play:, preschoolers

\section{Disciplines}

Education | Social and Behavioral Sciences

\section{Publication Details}

Verenikina, I., Kervin, L., Rivera, M. \& Lidbetter, A. (2016). Digital play: Exploring young children's perspectives on applications designed for preschoolers.Global Studies of Childhood, 6 (4), 1-12. 


\title{
Digital Play: Exploring young children's perspectives on applications designed for preschoolers
}

\author{
Irina Verenikina, Lisa Kervin, Maria Clara Rivera \& Alison Lidbetter
}

\begin{abstract}
This study builds on and contributes to research on digital play with young children. Previous research has examined digital play from different standpoints, but no studies have specifically addressed young children's perspectives as they interact with applications (apps) that have been designed for their age group. While our review of the literature provides insights that investigate young children's perspectives, there is limited research on preschoolers' views on the apps designed for them by adults. In this article we discuss young participants' perspectives on the apps that they engaged with in our research. In particular, we emphasise the importance of various contexts for digital play in relation to meaningful conversations and social interactions. Our findings provide insights about how children choose to engage in digital play and pose implications for the design of apps.
\end{abstract}

\section{Introduction}

The widespread proliferation of digital tablet technologies in educational settings and homes has stimulated an increased market of applications (apps) aimed at young children. Such apps, produced for either learning or simply entertainment, are designed in a playful manner to initially attract and then sustain children's attention. This is in line with understanding of developmental characteristics of young children where their play is seen as a major contributor to their cognitive and socio-emotional development (Vygotsky, 1978; Fleer, 2013). Most educators would subscribe to the notion that the most valuable early childhood learning experiences are playbased and this is true too in relation to digital technologies (Plowman \& McPake, 2013). Engaging in make believe play provides opportunities for exploration, experimentation, and manipulation that are essential for constructing knowledge. Such play helps develop children's imagination and creativity which are key for their cognitive, social and emotional development (NAEYC, 2009).

However, children's play within a digitally mediated context is significantly different from traditional imaginative play: while the latter is free and self-regulated, the design features of the apps largely shape the former. Children's digital play varies significantly in response to the apps they interact with. Many popular educational games are dependent upon drill and practice, which is easily programmed. However, relying just on drill and practice doesn't capitalise on the full potential of interactivity and experiential learning that are possible through digital games (Lieberman et al, 2009). When digital games are designed well they "can provide rich, fun, interactive experiences that can foster young children’s learning, cognitive development, skill 
building social interactions, physical activity, and healthy behaviours” (Lieberman et al, 2009, p.299).

This raises the question of how (and whether) playing with apps supports children's traditional play. Further, we ask what possible developmental benefits may be offered, and which apps are most conducive to learning and development (both cognitive and social). In the most, adults design the apps, often using pre-determined and predictable coding scripts, within content areas that they anticipate children will be interested in. Gaining children's perspectives on the apps that are produced for them would provide insights in what apps' characteristics best suit children's interests and abilities. We acknowledge young children are spending more time playing with the apps on increasingly available mobile digital devices, therefore they deserve the right for their opinion to be taken into account when designing digital products for them (Stålberg, Sandberg, Söderbäck \& Larsson, 2016).

Previous research has been conducted on the essential characteristics of applications for digital tablet technologies which provide opportunities for young children to engage their imagination and have a positive effects on their development and learning (Verenikina \& Kervin, 2011; Marsh et al., 2015; Johnson and Christie, 2009; Melhuish \& Fallon, 2010; O’Hare, 2014). However, this research is mostly focused on the views of adults including educators, families and software designers. There is limited research that has specifically addressed young children's perspectives on the applications designed for their age group, for digital tablets. This is not surprising as gaining very young children's perspectives is not an easy matter and "researchers have pointed out challenges, paradoxes and dilemmas in relation to young children in research" (Schiller \& Einarsdottir, 2009, p.126).

Research with children as participators and contributors demonstrates that even very young children are capable, competent, and active thinkers who have views on issues that affect them (Schiller \& Einarsdottir, 2009). By actively listening to children's opinions as they interact with materials designed for them, the researcher as co-learner, engages in a mutual exchange of information that has the capacity to improve teaching and learning and allows decisions to be made with children and not just for them (Clark, 2010; Danby \& Farrell, 2004; Lundy, 2007). Despite children's competence, child-friendly methods are often necessary because of children's marginalised social status and consequent lack of power in interactions with adults. (Harcourt, Perry \& Waller, 2011).

It is noted that children and adults need time to negotiate a new power structure in which neither adults nor children are completely in charge. It is difficult for an adult to step into a child's world and likewise it is not easy for a child to step into an adult's world (Druin, 2002). Yet, it is interesting to note that it is adults that most often create materials for children to interact with. Children need to learn that their ideas are valuable and should be heard and listened to by adults. In taking this position, researchers (mostly adults) need to acknowledge that children are not only to be observed, but can be incorporated within research partnerships.

Researchers focused on children and technology report on a number of difficulties of capturing such perspectives. For example, Druin (2002) cites many challenges encountered when researching the perspectives of children regarding technology. One of the important obstacles 
when researching with young children is that they have difficulty verbalising their thoughts, especially when it concerns abstract concepts and actions. Children can be extremely honest in their feedback and comments concerning technology, but much of what they say may be in their actions and therefore needs to be interpreted within the context of concrete experiences (Druin, 2002).

Work with children in authentic environments can be messy. It can be easy to lose track of ideas or data generated by the team (comprised of children and adults). A combination of data capturing methods needs to be utilised so that information, ideas and data is not lost (e.g. journal writing, video camera observation, team discussion and debriefing). Children may be frustrated with the lack of control or become disinterested in the activities. They may have challenges with the actual technologies they are using, testing or helping to inform. They can feel frustrated and disappointed in the process, which can lead to future uncooperative users, testers or informants (Druin, 2002). In Lundy’s (2007) study “not having a say in the decisions made about them was the single most important issue to children” (p.929). Lundy (2007) further states that valuing children's opinions is not just good pedagogy but is also a legally binding responsibility. The United Nations Convention on the Rights of the Child states that "[w]hen adults are making decisions that affect children, children have the right to say what they think should happen and have their opinion taken into account” (UNICEF, 1989, Article 12).

Young children have a natural desire to actively and collaboratively construct knowledge, with development and learning as the expected result of interactive processes. Keeping in mind the capabilities of children aged 3 to 5 years (NAEYC, 2009), technology is appropriate when it takes advantage of children's innate need to construct knowledge with others and respects the distinctive challenges presented by children's developmental characteristics, needs and interests in terms of age, individual differences and cultural contexts (Rosen \& Jaruszewicz, 2009). Exploratory play and social interaction are obviously important to young children and should be encouraged in the development of any application of digital technology for 3 to 5 year olds. Lundy (2007) has pointed out that children should not only be given the opportunity to express their views ("listened to"), but they have to be "facilitated" in this process and their views should be "acted upon, as appropriate" (p. 933). Children should be "involved in decision-making processes" and "share power and responsibility for decision-making” (Coleyshaw, Whitmarsh, Jopling, \& Hadfield, 2012, p.12).

\section{The Study}

The findings presented in this paper are part of a larger project funded by the Australian Research Council (Verenikina, Kervin \& Murphy, 2014) which aims to explore the ways that young children's traditional, spontaneous imaginative play manifests itself when young children make use of modern digital technologies in a variety of contexts. Three perspectives that have been researched included early years educators (survey and interviews), families (individual interviews and focus groups) and children (observation in different contexts). Our ultimate aim in the project is to look across our data to inform our knowledge and representation of children's perspectives, building on those described in the literature (e.g. Coleyshaw et al., 2012). Through our study children are listened to (as we observe their play); they are encouraged to express their views (within their social context and with adult scaffolding), but are also involved in decision- 
making processes (bringing their own device, sharing their favourite apps, choosing apps from App store) and share power and responsibility for decision-making (with our culminating activity of supporting children to design an app for other children). In this paper we focus on children's perspectives as captured through our observations, where the research question that guided us was: "How do young children respond to the applications for mobile digital technologies offering varying opportunities for play?” In our analysis we draw on our range of methods for gathering children's perspectives as we consider what these tell us about children's enactment of digital play.

\section{Approach}

In our study we acknowledge that children's play is a major developmental influence in the early years (Vygotsky, 1978; Lillard et al, 2014). Considering the significant role of children's traditional imaginative play for their development, and a recently increased "technologisation of childhood" (Plowman, McPake \& Stephen, 2010, p.72), we argue that it is important to investigate the ways that the developmental benefits of such play can be supported, enhanced and further advanced by modern digital technologies, transforming the play activity itself into a Digital play (Verenikina \& Kervin, 2011).

We examined the characteristics of iPad apps and looked to the opportunities that these provide for pre-schoolers to engage in imaginative play. To do this, we developed a number of criteria based on the theoretical understanding of the importance of imaginative play in children's development (Vygotsky, 1978; DEEWR, 2009) and research on educational value of computer games (summarised in Verenikina et al., 2010). The criteria then were adapted to the use of apps for mobile digital devices (Verenikina \& Kervin 2011). In summary, these criteria include:

- Self-motivated and intrinsically fun: reaching goals is less important;

- Provide opportunities for acting in 'as if' situations and engage children's imagination where there is no right or wrong answer;

- Discovery-oriented path of play which presents opportunities for making choices, problem solving and visual transformation of images;

- Provides the facility to engage collaboratively rather than as single player.

Based on our criteria we selected the apps from the top-grossing pre-schooler apps from iTunes. Using our criteria, acknowledging that this was developed based on theory and research from adults' perspectives, we identified apps that matched our criteria. These selected apps were made available on iPads within the Digital Playgroup. Children were also invited to bring along the device they used in their own home which contained apps of their family's selection.

Coleyshaw and colleague (2012) identify the complexity of the notion 'children's perspectives', and its particular meaning in relation to different areas of children's practices and different aims of gaining such perspectives. In our study we acknowledged that to obtain children's perspectives we needed to understand what features of the selected apps and which contexts of their use are conducive to children's positive response in terms of what we called 'play effects" their intrinsic motivation, imagination and talk (both dialogic and private speech - after Vygotsky, 1986). We also looked at the features of apps which allowed for the merge of on- 
screen and off-screen activities which we have discussed elsewhere (Kervin, Verenikina \& Rivera, 2015).

In our research of children's perspectives we were aware that research with young children needs to be carefully orchestrated in relation to their age and cognitive ability (NAEYC, 2009). Special care needs to be taken to ensure that children's perspectives are not overpowered by adults' presence and talk (Lundy, 2007). Additionally, the context for the observation needs to be carefully arranged so children feel safe in a familiar environment (Dalli \& Te One, 2012, p. 230) and their ability to talk is maximised through social support (Pellegrini \& Bjorklund, 2004). Children's perspectives were carefully "listened to" and "facilitated" through a variety of contexts (Lundy, 2007; Coleyshaw, et al, 2012).

We encouraged children to express their views on their digital play through the contexts which were either pre-planned (we selected the apps, chose the location, invited families) or evolved (children choose which app to engage with, where to sit and with whom to communicate). Some of the evolving contexts were child initiated where children chose to play alone, with (or next to) their peers and siblings, or their parents and other adults. When playing with children adults were following children's initiative and used only generic remarks and questions to support children in voicing out their views. Providing children with choices and supporting their initiative allowed for involving them in 'decision-making processes' (Coleyshaw, et al, 2012).

The age of children participants ranged from 3-5 years (preschoolers) - the age when the developmental value of make-believe play is mostly evident (Elkonin, 2005). In the first year a small sample of ten families was purposively identified through a snowballing technique (Kervin et al., 2006). The criteria for selection of the participants included: families who had a child aged 3-5 and who had already been using digital mobile technologies in their homes. Following extended interviews with families, 10 children (3-5 years of age) were invited to the ESC together with their families.

Children attended one hour play sessions weekly (referred to as the 'Digital Playgroup') with 3-4 families attending at a time in different combinations subject to their availability. Siblings (both older and younger) were also invited to participate. The participants became familiar with researchers and with each other with some children knowing each other previously.

We recognize that "special consideration needs to be given to a specific context in which children are invited to participate” (Harcourt \& Conroy, 2011, p. 42). Playgroup was conducted at the Early Start Centre (ESC) built under Australian Government Funded strategic teaching, research and community engagement initiative (http://earlystart.uow.edu.au/index.html). The ESC provides a comfortable setting for young children with appropriate size furniture, outdoor area and other necessary facilities. It was a neutral location for families who were coming from different geographical locations with their older children enrolled in both public and private school systems.

Children were provided with opportunity to spontaneously engage with the purposively selected apps on individually provided iPads. They also had the option to bring their own device and engage with apps on that. The children were able to move freely in the space and choose to 
interact with the apps, physical toys, other children and/or their parents and researchers. The study was conducted in accord with the principles of research ethics and was approved by the University of Wollongong Human Research Ethics Committee. Parents gave their written consent and children verbally agreed to be part of research. It was explained to them that researchers are interested how children play with different apps and children agreed to be observed and videotaped.

All Digital Playgroup sessions were recorded by two tripod cameras which captured the general context of the play, the sounds and positioning of children in relation to other children and adults. Additionally, children were invited to wear head cameras (Kaiser Baas X80 Action Cameras with GoPro head strap and quick clip). The children appeared to be happy to wear the cameras while playing, however, they were allowed to take them off if they wanted to. Some children did remove their camera for part of the Digital Playgroup sessions, but no child declined the invitation to wear the head camera at all.

Sumsion, Bradley, Stratigos and Elwick (2013) used head cameras in their study of early childhood setting from infants' perspectives. While they acknowledge the importance of this method of viewing he place though children's eyes, they caution researchers to be mindful in interpretation of captured images which need to be considered in relation to the space ("where the image is made"), visual content ("the site of the image itself") and the interaction between the image and its spectator ("audiencing”) (Sumsion et al, 2013, p.171). In our study with digital teachnologies, using head cameras was essential to ensure that we capture the view of the screen of each child's play with particular apps, as observation of children's interaction with apps was an aim of the study, i.e. to explore how children respond to particular features of each app.

When necessary (and possible) the researchers also tried to captured data through video shots taken by handheld iPads. Parents were also encouraged to access 'spare' iPads in the environment and take footage too of anything they thought interesting. All data were downloaded at the end of each Digital Playgroup session and removed from individual devices. The data from various devices were then sychronised for the analysis of digital play of each of the child in relation of their interaction with the app, the context and children's talk. The data were analysed in relation to the opportunities which various contexts and methods of data capture provided for gaining children's perspectives as manifested in the play effects of motivation, imaginative (pretend) play and children's talk. The vignettes presented in this paper were transcribed and the texts, together with the synchronized videos, were analysed for emerging themes (Kervin at al., 2006).

\section{Findings and Discussion}

This section presents two vignettes captured through our data collection procedures with children's families and researchers present. Our discussion of these vignettes is built around the contexts of digital play and play effects in relation to the features of the apps. Such analysis enabled us to ask the questions: how do children choose to interact with apps? What are the key contextual influences upon these interactions? And how is gaining children's perspective allowed us to reflect on our criteria in relation to digital play with pre-selected apps 


\section{Vignette 1: Peers playing side-by-side}

Context. This vignette presents the digital play of two boys, Oliver (4 years, 10 months) and Riley (4 years, 4 months), who have established friendship outside of the research project. An over 20 minute episode of their sustained play was captured by handheld iPad, tripod camera and O's head camera. Data captured by handheld camera was sufficient for analysing this episode - it allowed us to see the screen and follow the children's interaction. During the whole episode the children were sitting on beanbags next to each other.

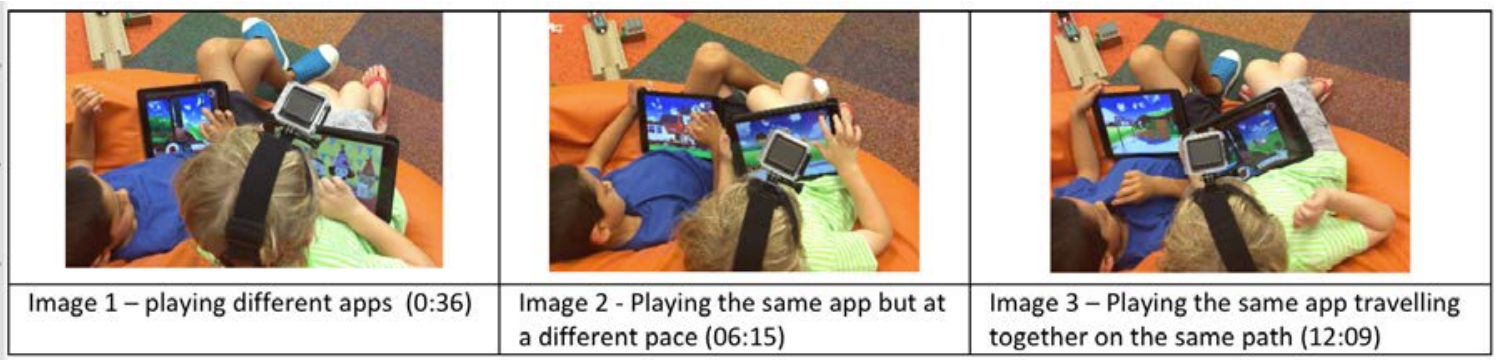

Figure 1: Footage of Oliver's and Riley's digital play captured by handheld device

At the beginning the children played two different apps: Toca Train (Riley) and Playtime (Oliver) (image 1). This lasted approximately 6 minutes. During this time children did not interact with each other or talk (Oliver only said 2 words), but looked occasionally at each other's screens. Riley was regularly blowing the whistle. Then Oliver decided to play Train too, saying, "I am going to play trains, I will be Woo-Hoo!” Riley provided Oliver with some tips (e.g. how to make a sound or pick up a passenger). They were articulating what they were doing. After approximately 6 minutes of maneuvering the trains the boys managed to play at the same spot with Oliver commenting, "We just both leave the crane”. They were telling each other where they were in their play, trying to stay on the same path. For example, they were letting each other know by blowing the whistle that they were 'leaving the station'. Both continued talking aloud when they interacted with the characters in the game (e.g. "Hello little girl”). Oliver collected a full carriage of passengers ("My train is full") and tried to talk to some of them in a personalised manner but then 'booted everyone out' of the train, thus engaging in makebelieve. Oliver explained to Mum that he got everyone off the train "because there is a fire" and he added that it was "for real", that he "saw" it and then "called 000".

The boys then had conversations about cargo they could load, or the passengers they had to pick up and were doing so in a play context, as if they were train drivers.

\section{Discussion.}

The analysis of play effects in this episode demonstrated that Riley and Oliver were motivated to play, as they sustained the engagement for at least 20 minutes and were focused on the screen for most of the time. Even though they were sitting close to each other during the whole episode and were familiar with each other, their communication was distinctly different in different social contexts facilitated by the apps. When they played different apps they did not interact verbally, but were aware of what was on each other's screens. They hardly said a word, not even accompanying their play by talking aloud, as young children often do (private speech,Vygotsky, 1986). This serves as a reminder that children's apparent confidence with technology does not 
necessarily equate to meaning making. While our data shows that the children were progressing through the app, without verbal annotation this made it difficult for researchers to tune into their perspective, what their play meant to them and whether they engaged their imagination. It also brings up the point about the developmental value of children's talking when they play. The absence of talk when playing apps individually (even when children sit next to each other) is alarming. Research in children's private speech indicates that children talk aloud more if they are with other children compared to playing alone (Vygotsky 1986). In this case we observed that close proximity to another child when using technologies did not result in any private speech. This is, arguably, can be attributed to interactive features of the apps which occupied children's attention. This unwelcome effect of electronic devices has been noted in recent research. For example, Sosa (2016) demonstrated that mothers and babies engaged in significantly less talk when playing with digital device compared to their play with traditional toys.

When these children played the same app but on different screens, with different timings and different patterns, their interactions changed: they spoke to each about features of the apps but also engaged in self-talk related to what they were doing without actual dialogue. The app did not support these children's attempts to engage in communication with and personify the characters (passengers) which were included in the app design.

The most engagement through dialogue occurred when the children tried to 'match up' their play and while still on different devices, they were travelling together through the same stations, discussing what they were doing and engaging in imaginative play. Their imaginative play however mostly followed the plot line suggested by the app. We did capture one instance where the play, did extend beyond the app.

The children seemed to be relaxed, and were drawn into the game as they used its interactive features - blowing the whistle, experimenting with the speed and operating the crane, as well as dealing with the passengers. However, they needed to have a common point of reference to sustain meaningful interaction as Oliver and Riley did as they successfully attempted to synchronise their play and subsequent interactions.

\section{Vignette 2. Interactions of siblings in digital play}

Context. Two brothers, Oliver and Luke (aged 4 years, 8 months and 2 years, 5 months) sit alongside each other on beanbags. The boys each have a small packet snack and balance their iPads on their knees as they eat and play. They were captured for a sustained episode of almost 10 minutes as they played TocaBoca Hairsalon. This play seemed to be guided by two main interactions; the first when Oliver used a photograph of Luke, the second when Oliver used a photograph of himself. For the purposes of this article, we focus on the first half of this interaction. Figure 2 presents still images taken from footage obtained from Oliver's head camera. The data was mostly captured by Oliver's head camera, but simultaneous recording by tripod camera was used to transcribe Luke's talk. 


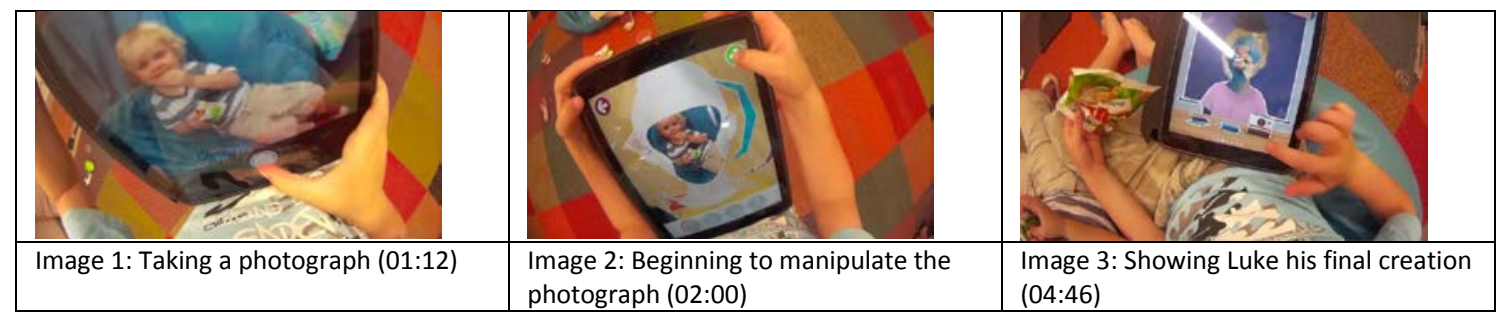

Figure 2: Key moments from Oliver’s head camera footage

Oliver plays the TocaBoca Hairsalon app. He selects the camera icon and holding the iPad calls Luke's name and photographs his brother. Oliver shows Luke the photo. Oliver experiments with the options within the app as he uses the photo in different face shapes and tries to use the settings to indicate where on the photo the eyes and mouth are.

Luke watches what Oliver is doing. Oliver acknowledges his brother and says, "Look [Luke] this is you!” as he continues to manipulate the image. Luke physically moves closer to Oliver and puts his own iPad aside. For the next two minutes, Luke sits close beside Oliver watching every change, giggling in affirmation when he is happy with what Oliver has done.

Oliver turns and talks to Luke identifying that he has finished, then tilts the screen to enable Luke to have a front-on look at what he has created. There is a verbal exchange between the boys before Oliver calls to their mother to have a look at what he has done.

\section{Discussion}

This vignette demonstrated that playing TocaBoca Hairsalon app enabled Oliver and his younger brother to sustain an episode of self-directed make-believe play of 'Hairdressers' for an extended period of time. This was accompanied by a sustained and meaningful communication with each other within their play. Being able to insert a personal photograph (captured of his brother) added personal meaning and created a motivational force for play: having his photo used was a good enough reason for Luke to abandon what he was doing to be part of his brother's play as observer, but also as a 'virtual' participator in the role of hairdresser's customer. In turn, Luke appeared an important motivator for Oliver in his play. As he made changes to the image, he made comments like, “[Luke], that’s you!”

The boys' mother was called upon to validate the experience as she was invited to see the final product. The mother's technical expertise was also requested and required by the older brother at some points of play, but interestingly, she was peripheral to the main experience and was removed by the child once the needed knowledge had been obtained. This indicates that Oliver felt in control of their environment and included his parent by his request when he considered support necessary.

This environment proved to be stimulating for verbal communication which is essential for children's development and well as capturing their perspective. The play-stimulated dialogue was framed by the app but it is the ability to personalise the play through inserting their photos which focused their attention in joint play. There were some connections made to outside knowledge too as features within the app were related to family experience (for example, a 
hairstyle was announced to be 'like dad!'). Oliver's play was further motivated by his younger brother's interest and enthusiasm for what he was doing. We captured instances where Luke encouraged his older brother to keep going - "keep doing my hair”. The data captured by Oliver's head camera enabled us to tune into Oliver's perspective as it provided close shots of his iPad screen. This coupled with footage from the tripod enabled us to also capture the interactions between the brothers and other people present at the location.

\section{Conclusion}

Methodological approaches to document children's activities and emerging conversations are valuable in helping us understand the children's perspectives as they engage in play facilitated by specially chosen apps. The importance of various contexts in shaping children's digital play (the ways that interactions with peers and adults unfold, the location and space it is situated, and the ways that they engaged with the apps) was highlighted. Observing our young participants' digital play within these contexts provided interesting insights in children's perspectives as manifested in their motivation, the episodes of imaginative play and talk.

Our findings demonstrated that our young participants responded positively to the apps selected based on our criteria as they were able to engage in sustained episodes of make-believe play and employed both private and social speech. The two vignettes provided in this article present children's responses to apps that were purposively selected with the use of our emerging criteria. Children were in control of their play and were able to progress through it at their own pace. The ability to personalise the play by embedding their own photos (Hair Salon) was an important characteristic in the digital play.

However, children's digital play in response to these purposively selected apps was also limited. In the TocaTrain app, children attempted to interact with the human characters (passengers) but those interactions were restricted by the app. Children's conversations and their make-believe were bound within the parameters in the apps. For example, language was mostly linked to the content and the sequences of play available within the app. Some connections were made to outside knowledge but these were minimal and required careful attention of a significant other to acknowledge and extend upon ideas.

The apps direct digital play in terms of the opportunities it presents, the play frames children can work within and the types of language stimulated. However, it is the child who has the power to choose how to play - the length of time, interaction and involvement of others, what they do within the app and their use of external stimulus. Our research showed that children are more empowered when they play with others and are more likely to capitalise on the affordances of the apps. Social interactions with others are essential in supporting, validating and extending children's digital play.

However, the simple presence of others such as peers or sibling playing alongside the child does not stimulate meaningful verbal communication. In our study, even when children were familiar with each other, playing separate apps alongside each other did not stimulate talk. In fact, it even seemed to inhibit them talking aloud. We know that talk is highly important to children in their traditional imaginative play, however we are yet to explore the influence of talk on children's 
development in digital play. It can be argued that the features of 'interactivity' which modern apps often contain have the ability to motivate children and sustain their play but at the same time can draw them into 'interaction' with the app itself which might diminish their social awareness, and therefore their private speech. This brings up a question in relation to the criteria for developmentally sound apps for young children: what is an optimal balance of 'interactivity' there? So that the features of interactivity motivate children to engage in play but on the other would not inhibit their social interactions and their talk. And what are the play contexts that we want to encourage?

In the instances of digital play that we captured, children were more likely to engage in meaningful conversations when they were involved in play together, doing similar things and coordinating their actions. Various communication contexts stimulate different ways for children to engage with digital play. This frames perhaps one of its leading characteristics - the social nature of digital play, if we want it to mirror the developmental benefits of traditional imaginative play for young children.

In our research the location of the Digital Playgroup within the Early Start Centre was important. This context enabled the children to make choices within pre-arranged features of the playgroup (such as which apps to play with) as they directed its evolving nature (where to play and whom to play with). This location, coupled with existing familiarity amongst our young participants also encouraged more extended verbal communication, which provided opportunities for us to capture children's perspectives.

We need to gather children's perspectives to enable us to understand their digital play - what it is that they are interested in and how this supports them as users of technology in ways that are meaningful and appropriate to what we know about play. We also need to understand the interaction patterns (with the device and with others) children naturally employ when using technology to understand how to best capitalise on young children's digital play.

\section{References}

Clark, A. (2010). Young children as protagonists and the role of participatory, visual methods in engaging multiple perspectives. American Journal of Community Psychology, 46(1-2), 115-123.

Coleyshaw, L., Whitmarsh, J., Jopling, M \& Hadfield, M. (2012). Listening to children's perspectives: improving the quality of provision in early years settings. Part of the Longitudinal Study of Early Years Professional Status. Research Report DFE-RR239b, University of Wolverhampton. https://www.gov.uk/government/uploads/system/uploads/attachment_data/file/183412/Df E-RR239b_report.pdf

Dalli, C. \& Te One, S. (2012). Involving children in educational research: researcher reflections on challenges. International Journal of Early Years Education, 20(3), 224-233

Danby, S. \& Farrell, A. (2004). Accounting for young children's competence in educational research: New perspectives on research ethics. The Australian Educational Researcher, 31(3), 35-49. 
Druin, A. (2002). The role of children in the design of new technology. Behaviour and Information Technology, 21(1), 1-25.

Elkonin, D. (2005). The psychology of play. Journal of Russian and East European Psychology, 43(1), 11-21.

Fleer, M. (2013). Play in the Early Years. Cambridge: Cambridge University Press

Harcourt, D., Perry, B. \& Waller, T. (Eds.). (2011). Researching young children's perspectives: Debating the ethics and dilemmas of educational research with children. NY: Routledge.

Harcourt, D. \& Conroy, H. (2011). Informed consent: Processes and procedures in seeking research partnerships with young children. In Harcourt, D., Perry, B. \& Waller, T. (Eds.). (2011). Researching young children's perspectives: Debating the ethics and dilemmas of educational research with children. NY: Routledge (pp. 38-51)

Johnson, J. E., \& Christie, J. F. (2009). Play and digital media. Computers in the Schools, 26(4), $284-289$

Kervin, L., Verenikina, I. \& Rivera, C. (2015). Collaborative onscreen and offscreen play: examining meaning-making complexities. Digital Culture \& Education, 7(2), 228-239 http://www.digitalcultureandeducation.com/cms/wp-content/uploads/2015/12/kervin.pdf

Kervin, L., Verenikina, I. \& Rivera, C. (2016, in press) Digital play and learning in the home: Families’ perspective. In Danby, S., Fleer, M., Davidson, C. \& Hatzigianni, M. (Eds). Digital Childhoods. Springer

Kervin, L., Vialle, W., Herrington, J. \& Okely, T. (2006). Research for Educators. Melbourne, Australia: Cengage Learning.

Lieberman, D. A., Fisk, M. C. \& Biely, E. (2009). Digital games for young children ages three to six: From research to design. Computers in the Schools, 26(4), 299-313.

Lillard, A., Hopkins, E., Dore, R., Palmquist, C., Lerner, M. \& Smith, E. (2013). Concepts and Theories, Methods and Reasons: Why Do the Children (Pretend) Play? Psychological Bulletin, 139(1), 49-52

Lundy, L. (2007). 'Voice'is not enough: conceptualising Article 12 of the United Nations Convention on the Rights of the Child. British Educational Research Journal, 33(6), 927942.

Marsh, J., Plowman, L., Yamada-Rice, D. et al. (2015). Exploring Play and Creativity in PreSchoolers' Use of Apps: Final Project Report. http://www.techandplay.org/TAP_Final\%20Report.pdf

Melhuish, K. \& Falloon, G. (2010). Looking to the future: M-learning with the iPad. Computers in New Zealand Schools: Learning, Leading, Technology, 22(30) https://core.ac.uk/download/files/677/29198811.pdf

NAEYC (2009). Position Statement on Developmentally Appropriate Practice http://www.naeyc.org/positionstatements/dap

O’Hare, E. (2014). Mobile Apps for Children: Criteria and Categorisation. OnlineSubmission. Research Report, Netherlands: http://www.cinekid.nl/sites/cinekid.nl/files/bijlage/Research 20Repor - Mobile Apps for Children.pdf

Pellegrini, A. D. \& Bjorklund, D. F. (2004). The ontogeny and phylogeny of children's object and fantasy play. Human Nature, 15(1), 23-43. 
Plowman, L. \& McPake, J. (2013). Seven myths about young children and technology. Childhood Education, 89(1), 27-33.

Plowman, L., McPake, J., \& Stephen, C. (2010). The technologisation of childhood? Young children and technology in the home. Children \& Society, 24(1), 63-74.

Rosen, D. B. \& Jaruszewicz, C. (2009). Developmentally appropriate technology use and early childhood teacher education. Journal of Early Childhood Teacher Education, 30(2), 162171.

Schiller, W. \& Einarsdottir, J. (2009). Special Issue: Listening to young children's voices in research-changing perspectives/changing relationships. Early Childhood Development \& Care. 179(2), pp.125-130.

Sosa, A. V. (2016). Association of the type of toy used during play with the quantity and quality of parent-infant communication. JAMA Pediatrix, 170(2): 132-137

Stålberg, A., Sandberg, A., Söderbäck, M., \& Larsson, T. (2016). The child’s perspective as a guiding principle: Young children as co-designers in the design of an interactive application meant to facilitate participation in healthcare situations. Journal of biomedical informatics, 61, 149-158.

Sumsion, J., Bradley, B., Stratigos, T. \& Elwick, S. (2013). 'Baby Cam’ and Participatory Research with Infants: A Case Study of Critical Reflexivity. In Fleer, M. \& Ridgway, A. (Eds.) Visual Methodologies and Digital Tools for Researching with Young Children (pp. 169-191). Springer International Publishing.

UNICEF (1989). Convention on the Rights of the Child. A summary of the rights under the Convention on the Rights of the Child www.unicef.org/crc/files/Rights_overview.pdf

Verenikina, I. \& Kervin, L. (2011). iPads, digital play, and pre-schoolers. He Kupu: The Word, 2(5), 4 -19. Retrieved March 2016 from http://www.hekupu.ac.nz/index.php?type=journal\&issue=15\&journal=262

Verenikina, I., Herrington, J., Peterson, R. \& Mantei, J. (2010). Computers and play in early childhood: Affordances and limitations. Journal of Interactive Learning Research, 21 (1). 139-159

Verenikina, I., Kervin, L. \& Murphy, C. (2014). "Conceptualising digital play: The role of tablet technologies in the development of imaginative play of young children", Australian Research Council, Discovery Project (ARC DP 140100328).

Vygotsky, L. S. (1980). Mind in society: The development of higher psychological processes. Cambridge, Mass.: Harvard university press.

Vygotsky, L. S. (1986). Thought and Language. (Edited by A. Kozulin). Cambridge, MA: MIT Press.

\section{Acknowledgments}

This research is supported under Australian Research Council's (ARC) Discovery Projects funding scheme (DP140100328, Verenikina, Kervin and Murphy, 2014-2016, “Conceptualising digital play: The role of tablet technologies in the development of imaginative play of young children”). 